\title{
A Design for Planning the Cleanup of Formerly Used Radium-Contaminated Sites
}

\author{
A. H. Voelker
}




\section{DISCLAIMER}

This report was prepared as an account of work sponsored by an agency of the United States Government. Neither the United States Government nor any agency Thereof, nor any of their employees, makes any warranty, express or implied, or assumes any legal liability or responsibility for the accuracy, completeness, or usefulness of any information, apparatus, product, or process disclosed, or represents that its use would not infringe privately owned rights. Reference herein to any specific commercial product, process, or service by trade name, trademark, manufacturer, or otherwise does not necessarily constitute or imply its endorsement, recommendation, or favoring by the United States Government or any agency thereof. The views and opinions of authors expressed herein do not necessarily state or reflect those of the United States Government or any agency thereof. 


\section{DISCLAIMER}

Portions of this document may be illegible in electronic image products. Images are produced from the best available original document. 
Printed in the United States of America. Available from National Technical Intormation S'ervice

U.S. Department of Commerce

5285 Port Royal Road. Springfield, Virginia 22161

Price: Printed Copy $\$ 5.25$; Microfiche $\$ 3.00$

This report was prepared as an account of work sponsored by an agency of the United States Government. Neither the United States Government nor any agency thereof, nor any of their employees, contractors, subcontractors, or their employees, makes any warranty, express or implied, nor assumes any legal liability or responsibility for any third party's use or the results of such use of any information, apparatus, product or process discloșed in this report, nor represents that Its use by such third parly wuuld not-infringe privately owned rights. 
Contract No. W-7405-eng-26

REGIONAL AND URBAN STUDIES

ENERGY DIVISION

A DESIGN FOR PLANNING THE CLEANUP OF FORMERLY USED RADIUM-CONTAMINATED SITES

A. H. Voelker

Date Published: April 1978

NOTICe Tlis ducument contalns infopmation of a prelıminary nature. It is subject to revision or correction and therefore does not represent a final report.

OAK RIDGE NATIONAL LABORATORY

Oak R1dge, Tennessee 37830

operated by

UNION CARBIDE CORPORATION

for the

DEPARTMENT OF ENERGY

This report was propared as an accoutit of wourh spansored by the United States Government. Neither the United States nor the United States Department of Energy, nor any of their employees, nor ony of their contractors, subcontrastons, of their employeos, makes any warranty, express or implied, or assumes any legal liability or responsibility for the accuracy, completeness ut usefulness of any information, apparatus, product or process disclosed, or represents that its use would not infringe privately owned rights. 


\section{THIS PAGE}

\section{WAS INTENTIONALLY \\ LEFT BLANK}


TABLE OF CONTENTS

$\underline{\text { Page }}$

ACKNOWLEDGMENTS • • • • • • • • • • • • • • • • • • • • • • • v

ABSTRACT • . . . . . . . . . . . . . . . . . . . . . . . . 1

1. INTRODUCTION . . . . . . . . . . . . . . . . . . . 1

2. THE PROBLEM . . . . . . . . . . . . . . . . . . . 5

2.1 A Gruwing Concern . . . . . . . . . . . . . . . . 5

2.2 The Cleanup Effort . . . . . . . . . . . . . . . . 5

2.3 The Nature of the Radiation Hazard . . . . . . . . . . 8

2.4 The Complexities of the Cleanup Problem......... 9

3. A PLANNING PROCESS DESIGN . . . . . . . . . . . . . 17

3.1 Process Attributes . . . . . . . . . . . . . 17

3.2 Public Participation ............... 19

3. 3 Group Processing Techniques . . . . . . . . . . . . 22

3.3.I The Nominal Group Technique . . . . . . . . . 24

3.3.2 The Take-Part Process . . . . . . . . . . . 25

3.4 The Management Plan Development. Process . . . . . . 26

4. CONCLUSION . . . . . . . . . . . . . . . . 35

REFERENCES ........................ . . 37 


\section{THIS PAGE \\ WAS INTENTIONALLY \\ LEFT BLANK}


The author thanks D. G. Jacobs of the Office of Environmental Policy Analysis and H. W. Dickson of the Health and Safety Research Division at Oak Ridge National Laboratory for their technical review and patient tutoring in the problems of the decontamination and decommissioning of radiumcontaminated facilities, a truly baffling area for the uninitiated. 


\section{A DESIGN FOR PLANNING THE CLEANUP OF FORMERLY USED RADIUM-CONTAMINATED SITES}

A. H. Voelker

ABSTRACT

The decontamination and decommissioning of radium-contaminated facilities no longer in use have received increased attention in recent years. However, planning cost-effective cleanup solutions that are acceptable to the major groups concerned with nuclear waste management has proved to be a signficant stumbling block. The decision maker must objectively and efficiently consider trade-offs between various concerns, choose an appropriate solution, and convince an uneasy public that properly decontaminated and decommissioned facilities can be safe for future unrestricted use.

Fortunately, new procedures to assist the decision maker in performing these duties are evolving, and this report suggests how these procedures can be adapted to a proposed planning process for the decontamination and decommissioning of formerly used sites. The proposed process has the attributes of continuity of responsibility, centralized authority, sensitivity to diverse concerns, flexibility, consensus seeking, alternative plan generation, and objectivity. Special emphasis is placed on means of opening the decision-making process to broader participation by interested parties and on generation of alternatives.

\section{INTRODUCTION}

This report proposes a process by which the Department of Energy (DOE) and the Nuclear Regulatory Commission (NRC) can accomplish the next step in their expanded activities to clean up formerly used radiumcontaminated facilities under their control. At the conclusion of the survey phase currently in progress, it will be necessary to generate management plans for the cleanup of individual sites, and special attention to this planning step is warranted by the nature of the problem facing DOE and NRC decision makers. They must gain the cooperation and concurrence for proposed plans from federal agencies, state and local governments, the nuclear industry, and a concerned public. They must convince an uneasy 
and skeptical public that properly decontaminated and décommissioned facilities can be safe for unrestricted future use. And they must do their planning with an eye to the political process, because Congress will undoubtedly exert influence upon and monitor the large sums of money involved. The problem faced by DOE and NRC cannot be handled by traditional engineering or economic solutions because such solutions tend to ignore institutional interrelationships, public inputs, and the trade-offs stemming from conflicting value systems.

Fortunately, the framework for an appropriate decision process is beginning to emerge from those disciplines curcerned with dec1sion making in modern society. The realization that decision making can be reduced to a serles of definable steps has led to the description of a generalized procedure with broad applicability. In this procedure, a decision maker first identifies diverse alternative solutions and then selects the superior solution through the systematic consideration of trade-offs. A number of decision aids have been devised through the years to assist in accomplishing the various steps in this general process. These aids range in complexity from formal analytical techniques to simple rules of thumb. Much of the current thought in this area has been integrated by Quade ${ }^{l}$ into a process that he calls "policy analysis." This process is superior to its predecessors, operations research and systems analysis, in that it attempts to be more than a purely rational, coldly objective, scientific method leading to a solution for every problem to which it is applied. Instead, it is a flexible general procedure incorporating the intuitive judgment of the decision maker and the political and institutional realities of the decision context.

This report will not attempt to describe in great detail the idealized decision process advocated by Quade. Rather, the report applies the principles of policy analysis directly to the problem of cleaning up the formerly used radium-contaminated sites. Section 2 introduces the cleanup problem, outlines its complexity, and proposes that an innovative decision process is essential if we are to make headway on what until now has been primarily an intractable problem. Section 3 then outlines the process. Special attention is given to group processing and public participation 
because these subjects receive scant attention in most texts dealing with decision making; yet the subjects are critical to the ultimate acceptance of any proposed solution. 


\section{THIS PAGE}

\section{WAS INTENTIONALLY \\ LEFT BLANK}




\section{THE PROBLEM}

\subsection{A Growing Concern}

The controversy surrounding other parts of the nuclear fuel cycle tends to obscure a rising murmur of concern about the disposal of lowlevel nuclear wastes. 'Although more attention is being given to such wastes, the issues still have to be focused sharply, and a factual base for dialogue must be established. At present, the debate is highly emotional and is often underlain with poorly defined moral issues. For instance, a recent front-page newspaper story contained the sentence, "Nuclear Regulatory Commission estimates of radon emissions from uranium tailings piles are 100,000 times too low, Walter Jordan, former Oak Ridge National Laboratory assistant director has told the NRC."2 It seems inconceivable that a responsible agency could make such an error until one realizes that the NRC bases its estimates on a different time period. The NRC limits its determination of emissions impact to that period for which direct benefit in the form of electrical power is derived from the uranium, a few decades at best. Jordan, on the other hand, considers the emissions impact over the total physical half-life of the contamination, many thousands of years. It is obvious that the parties start from different precepts. NRC takes the traditional position of the resource developer, while Jordan raises a difficult and totally new moral question: Do we have the right to assign costs in the form of potential health effects to future generations who cannot derive benefits from the exhausted resource? This perplexing issue is typical of the many questions surrounding low-level waste management.

\subsection{The Cleanup Effort}

Mili.tary applications and later commercialization of nuclear energy produced, over about 30 years, a number of obsolete facilities possessing some degree of residual contamination. Many of these facilities requiring decontamination and decommissioning were at one time used either in the extraction of uranium (mill tailings), the production of special nuclear 
materials, the development of nuclear energy, or for the testing of nuclear devices. The NRC has inherited the responsibility for those facilities that were formerly licensed by the Atomic Energy Commission (AEC). The DOE proposes to assume responsibility for those facilities that were operated under contract to the Manhattan Engineer District (MED) or the AEC and also for inactive uranium mill. sites. With the exclusion of the uranium mill...sites, the DOE facilities are known: as the formerly used MED/AEC sites: :-

:The total number of contaminated sites may be as large as several hundred, and radiological surveys are currently under way to ascertain the number. As one might imagine, the volume of contaminated material and the level of contamination is quite variable within this large group of sites. Removal of ás little as a few shovelfuls of contaminated soil may be sufficient to clean up a few sites. On the other hand, tremendous volumes of material must be considered at the uranium mill sites. For example, past marginal operations in the uranium mining industry have left 22 privately owned mills in eight westèrn states closed; including about 25 million tons of tailings containing $14,000 \mathrm{Ci}$ of radium together with assorted other radioactive decay products of iraniım. 3 :

The cleanup of formerly used sites must be viewed as a growing segment of a much larger effort, the general management and regulation of radioactively contaminated facilities, Decontamination and decommig= sioning have always been a part of this general management and regulatory responsibility of the government. However, four significant trends have forced increased attention to this activity.

First, an increasing number of facilities are becoming excess as: they reach the end of their useful lives. Second, the informal procedures of the past for releasing decontaminated facilities are being replaced by more detailed, formal guidelines. This situation has come about through pressure from concerned special-interest groups and by the fragmentation of regulatory responsibility. The responsibility for monitoring and managing radioactive substances has hrnatened with the split-up of the Atomic Energy Commission and the new role of the Environmental Protection Agency (EPA) in setting standards and with the acceptance of regulatory responsibility by some states.' The consequence of this spreading 
regulatory responsibility is that the actions of nuclear energy developers are more heavily scrutinized now than once was the case. Third, exposure levels contained in the guidelines for release of facilities are becoming tighter. These levels have decreased by at least a factor of 2 in the last 10 years. In some cases, sites previously released cannot pass today's guidelines and must be reexamined. Fourth, public concern wi.th low-level nuclear waste disposal has escalated rapidly in recent years. Dramatic media events, such as the discovery of uranium mill tailings being used as construction material in Grand Junction, Colorado, and the large-scale thefts of contaminated material from a waste dump near Beatty, Nevada, :have put tremendous pressure on both the federal and state agencies concerned with nuclear regulation to promulgate standards and criteria, perform research on decontamination, and begin work on , comprehensive cleanup plans.

A number of experimental and demonstration decommissioning projects have been carried out over the years. ${ }^{4}$ These projects included power reactors, university reactors, and accelerators. However, these projects have not resolved fully the many engineering, economic, and safety questions surrounding radium-contaminated facilities, and a number of studies and surveys are still in progress. For instance, BattellePacific Northwest Laboratories is investigating the various aspects of decommissioning fuel cycle facilities and commercial power reactors for the NRC. Also the NRC is preparing a generic environmental impact. statement on uranium milling to examine mill-tallings reclamation and financial surety arrangements. The DOE is currently surveying MED/AEC sites for possible contamination that had not been cleaned up when AEC released them.

Because of time constraints, long-range action plans will have to be formulated before all the research and survey work is finished.: DOE has already begun work on a 5-year plan for the orderly decontamination and decommisstoning of a large number of facilities. In addition to difficult technical problems, such a plan must consider the jurisdictional responsibilities of the various agencies and governmental units involved and the minimum standards acceptable to various governmental units. To be most useful, the plan must include a description of the 
general site level planning process and a schedule by which sites are to be decontaminated. Describing a site level planning process that could be included in the general plan is the primary purpose of this report. To understand the details of the process design described in the report, it is necessary first to explore the problem of cleanup at the site level. This is accomplished in Subsects. 2.3 and 2.4. Much of the. discussion centers on the mill-tailings sites because more information is published for this group of facilities. However, the discussion is generally applicable to all radium-contaminated facilities.

\subsection{The Nature of the Radiation Hazard}

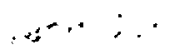

The exposure risks from contamined facilities are influenced both by the pathways leading to man and the longevity of the threat. This can be 1llustrated by the mill-tailings situation. Ores are crushed, ground, and chemically leached to remove uranium in the milling operation. The solid residual in the tailings from these steps is nearly equal to the input volume in ore and contains $85 \%$ of the natural radioactivity in the ore. By bringing the ore to the surface and concentrating the residual tailings in a pond, the radioactivity of the site is normally increased by several orders of magnitude above the average concentrations in the earth's crust. The tailings contain radium with a half-life of 1600 years. While radium itself is a long-term problem, even more serious is the fact that it continues to be produced in the tailings from the decay of ${ }^{230}$ Th which has an 80,000-year half-1ife. Radun gas, a product of radium, is another source of difficulty. It is released from tailings and diffuses rather freely through the air. Recently it was suggested that radon (primarily through its decay products or daughters) may actualiy be contributing significant exposures to persons at locations thousands of miles removed from the site. 5

The daughter products of radon, in turn, appear to cause cancer in the bronchi of the lungs. An EPA study estimates that the average individual exposed continuously over a lifetime to a nearby urantum pile could incur a $70 \%$ increase in the risk of bronchial cancer, a disease that is almost always fatal. EPA notes: "Since some of these sites are 
located in or near urban areas, large populations may be receiving these lung doses, thus increasing the health risk." 6

From the discussion above it is apparent that the pathways for radiation exposure from existing mill tallings are numerous and difficult and expensive to manage. In summary, they consist of the following major pathways:

1. inhalation of wind-blown particles;

2. inhalation of radioactive substances, including radon, released from the tailings;

3. excernal body exposure from the callings;

4. Internal exposure from ground- and surface water contaminated by the tailings; and

5. Internal exposure through the food chain.

Similar pathways can be described for any of the contaminated facilities, except that many of these facilities contain only surface contamination that can often be cleaned up by standard decontamination procedures.

\subsection{The Complexities of the Cleanup Problem}

Finding solutions to problems spawned by modern technology is becoming an exceedingly difficult and complex task. This fact clearly applies to the problem of nuclear decontamination and decommissioning. The solutions most often quoted are physical solutions, which seem straightforward and adequate when first considered. For example, the solutions commonly proposed for the mill tailings problem include:

1. using a soll cover to stablize a pile and reduce radiation levels;

2. maintaining a water cover or impoundment as a radiation shield over the wastes, which is feasible because taflings are ponded in the initial extraction phase; ${ }^{7}$ 
3. controlled containment in which site access is restricted and a11 pathways are carefully monitored for the total period of risk;

4. removing all contaminated material to a controlled site; and

5. putting the tailings back into the mine from which the ore has been extracted.

While these solutions minimize the risk of exposure to varying degrees and thereby reduce the probability of future health effects (illnesses plus. deaths) attributable to radioactive waste, they cannot satisfy those critics unwilling to accept even a minimum level of risk from nurlear energy and to objectively compare the risk of nuclear energy with other forms of energy. Even more important, these solutions do not satisfy those critics unwilling to assign risk to future generations. For instance, critics have suggested that water and wind erosion may uncover soilcapped tailings within decades. ${ }^{8}$ The Bureau of Mines found impoundment dams inexpensive and effective but subject to erosion and rupture ${ }^{7}$ and suggested that the use of precious western water for containing lowhazard waste may not remain politically feasible as competition for water grows. The third and fourth options require controlled containment, which demands a stable, responsible society for many centuries or millennia. Such containment has never been attempted before in human history, and there is no substantive evidence that it will be successful in the future. As to the last option, the volume of tailings is such that they cannot be contained totally in the mine from which they are taken, and the problem of aboveground storage of residue is not eliminated hy this option.

A second group of problems which complicates simple engineering solutions stems from institutional and societal interactions and responsibilities. No federal agency has clear authority over nuclear wastes. For example, the NRC regulates only material that is used as a source of uranium; once the uranium is extracted from the ore, NRC has no direct authority over the resulting tailings. The responsibility for the cleanup of inactive mill-tailings sites has been assumed by the Department of Energy and the Environmental Protection Agency. However, their 
respective roles as well as those of the various states are not well defined. At present there is a tremendous variability among the different states with respect to decontamination and decommissioning requirements for tailings sites.

The rights and wishes of local and state governments to set standards more stringent than the federal government will undoubtedly become more of an issue as regulatory responsibility broadens. For instance, New York City already prohibits the transit of nuclear wastes through the city, and various states have demanded veto power over waste disposal activities of the federal government, voicing the right of the state to regulate land use. In several instances, such as the Vitro mill-tailing site in Salt Lake City, local government has been quite active and has assumed the stance of a bargaining agency. It is obvious that, as time proceeds, the number of participants in waste management issues will increase and that their interrelationships will become more complex. A new set of participants is beginning to emerge, as evidenced by growing interest in low-level waste management among the articulate public and special-interest.groups. This has been documented in a recent systematic review of current literature. ${ }^{9}$

Another factor complicating decontamination and decommissioning is a growing awareness of the cost of cleanup and the maldistribution of the cost burden. When the West Valley, New York, nuclear fuel reprocessing plant owner decided in 1976 to transfer control of the site to the New York State Energy Research and Development Authority, it imposed a large financial burden on the state. ${ }^{4}$ Although the cost will undoubtedly run from the tens to the hundreds of millions of dollars, New York has set aside only $\$ 3,000,000$ to take care of the problem. The New York Authority has therefore asked DOE to take over completely the West Valley site.

As exemplified by the Vitro tailings site, economics and land use have begun to play a larger role in the management of contaminated facilities. Here the city has grown to surround a site that was formerly only sparsely developed, thereby increasing its attractiveness for other possible uses. However, recent studies 10 of the site have shown extenEive land contamination from blowing duet. Decontamination of thie land 
is necessary before new structures can be built on it; as a result, a ban exists on further building construction within one-half mile of the Vitro site. The value of the roughly 1000 acres affected by this restriction is estimated to be about $\$ 27,000,000$. For comparison, Biles ${ }^{3}$ lists a set of alternatives for moving and stabilizing the pile at a cost of $\$ 8,000,000$ to $\$ 31,500,000$ for differing degrees of effectiveness.

The variability of these alternatives and the high value of the land are the basis for much of the conflict concerning the Vitro site. If the federal government willingly pays to clean up the site, the local and state governments are likely to opt for the most costly solutions without much attention to costs vs henefits. 'l'herefore, it is probable that the final solution for the Salt Lake City site will involve an .. attempt on the part of the federal government to obtain a cost-sharing agreement from the state to achieve the most equitable solution. This action will involve negotiation, some of it undoubtedly on the floor of Cong:ess.

If any one thing characterizes formerly used radium-contaminated sites, it is their great diversity. They vary in level of contamination, physical characteristics, place and value in the local setting, and the . institutional entanglements that control their future disposition. Even the mill-tailings sites exhibit a great deal of variability. For example, the height of tailings piles among active sites varies from 3 to $230 \mathrm{ft}$. Radium has penetrated less than $2 \mathrm{ft}$ beneath the Vitro site tailings, while at Shiprock contamination has penetrated $20 \mathrm{ft}$ beneath one of the unlined solution ponds. Seven of the sites will be evaluated for possible removal of the tailings to other locations. However, this is not cunsidered necessary at the remaining sites. The buildings have been removed at some sites, while at others they are used for other purposes. One site is even a training ground for earth-moving marhinery operatore. Although the physical solutions for many of the MED/AEC sites are somewhat easier to implement because the volume of contaminated material is less than with tailings, the MED sites present especially difficult institutional problems. Many of them have changed ownership and are currently used by industries quite different from the nuclear industry that orginally occupied the facility. In addition, many of these sites 
are located in growing industrial or residential areas and have the potential for exposing increasing numbers of people to contamination levels higher than accepted standards.

For example, the recent radiological survey ${ }^{1 l}$ conducted on an 11-acre site in Hazelwood, Missouri, formerly used for the storage and drying of radioactive residues from uranium ore handling, revealed that the site was being prepared at the time of the survey for the manufacture of chemical coatings with apparent disregard or lack of knowledge of the extent of contamination of the site. The survey team found among other things that "a1pha and beta-gamma contamination levels on surfaces and crtornal gamma radiation levels at $1 \mathrm{~m}$ above surfaces exceed current NRC guidelines for the release of decontaminated property for unrestricted use over a large portion of the site." Also, "If reconstruction of the buildings is completed without removal of waste residues presently inside or near the structures, potentially hazardous ${ }^{222} \mathrm{Rn}$ daughter concentrations could develop inside some of the buildings." While most surveyed sites are not so much a problem as Hazelwood, they generally contain at least some areas with contamination levels higher than the guidelines. Many of these pockets of contamination are in buildings or have portions of buildings covering them. Displacing businesses and alarming workers is certain to present difficulties in future cleanup efforts.

There are some subtleties of decontamination which will greatly influence decisions relative to currently occupied sites. It is extremely difficult to ensure in advance that a building can be adequately decontaminated. It may require repeated attempts with no guarantee of final success. On the other hand, total removal of material also has inherent problems. Removing soil, for example, creates pockets of contaminated soil through the use of large, imprecise equipment such as bulldozers. Contaminated soil is sometimes moved from high ground to low spots in this manner. In addition, disturbing an area may enhance some paltways for contamination such as wind-blown dust. It is entirely possible that the increased health impacts to workers and nearby residents during cleanup of some sites would be greater than those that would be experienced 
if the site were left undisturbed. As a rcsult, the best decision for some remote sites may be to submit these sites to controlied containment without attempting cleanup for unrestricted releases.

The intent of the discussion to this point has been to demonstrate that the cleanup of formerly used sites will prove to be a complex, time-consuming, conflict-prone process. In summary, it has been shown that:

1. The lines of authority and responsibility among participating groups are confused, and this will prohahly hinite communication and delay the development and implementation of site management plans.

2. Numerous parties have input into the final determination for each site, including DOE, NRC, EPA, state and local governments, sperial= interest groups, and even Congress.

3. Genuine moral questions exist relative to management of contaminated property. The national debate is still evolving, and it is impossible to predict the changing position of varlous participants. Sile llallagement recommendations that are insensitive to this sociological reality will probably result in costly redirection, perhaps cnding in a second rleanup etfort at some future date.

4. No practical, foolproof, permanent way to eliminate the hazard for all existing sites is known. In essence, no guarantee of absolute safety is possible, and a minimal level of future monitoring is necessary. The management plans ultimately adopted will be cxpensive - in the hundreds of millions of dollars - thereby ensuring Congressional scrutiny.

5. Each site represents a unique set of problems, and no simple standard solution is likely to work at all sites.

It should now be obvious that the traditional approach of asking for bids from contractors to clean up a particular site to some predetermined radiation level and offering the lowest bid as the best 
recommendation for funding is an invitation for opposition, delay, and rejection. The approach is insensitive to sociological factors, some of which may be much more important than technical or economic considerations. It fails to involve those groups with the greatest concern and allows little flexibility for the inevitable negotiations involved in the final decision.

Is it possible to create a sensitive decision process that can generate site management recommendations leading to acceptance? Enough experience now exists with complex societal decision making that one can, through a systematic approach and the application of proven techniques, greatly improve the probability of. acceptance. Such a process is outlined in Sect. 3. Although much more design work is needed to actually apply the process, the concepts speak for themselves, and the outline is adequate to allow completion of a detailed design at a future date. 


\section{THIS PAGE}

\section{WAS INTENTIONALLY \\ LEFT BLANK}




\section{A PLANNING PROCESS DESIGN}

\section{1 Process Attributes}

A process capable of dealing with the formidable complexity surrounding contaminated facilities must possess the following attributes:

1. Continuity of responsibility and centralized authority. Centralized authority can only be achieved by designating a management team with sole responsibility for the cleanup of a particular group of sites through the entire cleanup process: the plan development, the plan modification, and the plan implementation. The team leader should be either a DOE or an NRC employee, depending on which agency has primary responsibility for the group of facilities. Such an assignment would help to guarantee continuity and, more important, would ensure close liaison between the work actually being done and the political climate of Washington.

2. Sensitivity. Any process adopted should be sensitive to the various interest groups and their relative power and should be able to incorporate them in the planning and implementation.

3. Flexibility. The process should allow negotiation and modification. Negotiation should be accepted as a normal part of the process, and a number of decision points should exist at which compromise and modification are possible.

4. Consensus seeking: No process will satisfy everyone concerned with radioactively contaminated property. However, the process should place importance on all positions, reconcile differences to the extent possible, and justify the final decision to those representing each position. Accepting the legitimacy of diverse interests in the planning process is both the strength and weakness of an open, technological society. It allows the society to act on new' and evolving concepts and to respond to a changing environment. On the other hand, multiple involvement complicates and delays decisions on controversial issues. But past difficulties with contaminated sites suggest that it is better 
to be relatively inefficient in the decision process than to seek expedient technical solutions.

5. Alternatives. A number of development plans have been abandoned in recent years as public opposition grew and then hardened because compromise either was not attempted or was impossible. Most of the projects involved offered no alternatives in the public debate and allowed interested parties to be only for or against the proposed solution." Past site-location decisions for nuclear power plants are classic examples of such confrontations.

Public debate of site cleanup alternatives cannot relieve the management-plan development team from the necessity of selecting and defending a single "best" final alternative, but it can help to inform the team and allow them to assess better the acceptability of various solutions.

6. Objectivity. Complexity and the differing value systems of the interested parties preclude the generation of a totally acceptable solution to the facilities problem by purely objective means because subjective input is required to make some of the difficult trade-off's. For : instance, the results of cost/benefit analysịs may be subverted by political considerations or undue concern for safety. However, if a planning process is to be both successful and open, it must be defendablc and therefore incorporate systematic procedures to the extent possible which can be explained and which possess a degree of objectivity. In this context, systematic procedures are a series of preplanned steps satisfying some criteria and having a reasonable expectation of reaching the stated goals. For the facilities effort, this requires a planning process with the attributes defined in this section, working toward a goal of cleaning up sites at a reasonable cost and in a reasonable time period. Objective procedures then become components of the generalizen systematic procedures being suggested, for example, techniques for considering trade-offs between alternatives such as cost/benefit analysis. These techniques should be considered as decision-making tools.

The attributes above form the basis for the process design discussed in this report. But before the proposed planning process is described, it is useful to discuss the following two concepts upon which much of the process is based. 


\section{2 Public Participation}

In the last 15 years, the public has become increasingly involved in the many development decisions affecting it directly. This trend has been accelerated by government programs encouraging politically powerless groups such as the urban poor and the Indians to become more active and by the widespread environmental movement. The premise underlying this trend seems to be that, in general, broadly. based decisions are superior in achieving societal goals. Although this premise is consistent with our concept of democracy, it is quite impossible to prove. However, one can substitute another demonstrable premise in defense of public participation: in this country a planning process cannot long remain out of phase with the current concerns and philosophy of the majority. As an attitudinal change spreads throughout the population, it eventually becomes institutionalized by means of the formal political process. For example, the environmental movement spawned the Environmentai Protection Agency through the political process, and it now guards the interests of environmental concerns. To avoid bucking the power and pervasiveness of such movements, an effective planning process must be sensitive to the constantly changing matrix of values which is characteristic of our society, preferably in advance of the main movement. By incorporating public participation in the planning process, the decision maker can remain aware of public opinion as well as be in a better position to judge the strength of this opinion at any time.

Although desirable and even necessary, public participation is a difficult resource to tap. To begin with, there is no single public but, rather, numerous diverse groups having differing amounts of information, political astuteness, and political power. Fortunately, it is possible to deal with this confusing array of groups by organizing them

into a logical hierarchical grouping such as suggested by Bronfman. ${ }^{9}$ The first level of her hierarchy is a simple division into at tentive and unattentive portions of the total population. The Canadians demonstrated that a large percentage of the public is precluded from participating in the nuclear debate because of disinterest or a general ignorance of the issues. Some $44 \%$ of the Canad1ans surveyed in March 1976 did not know 
that nuclear power could be used for the production of electricity. 12 Thus a large part of the total population is likely to be precluded from effective participation biy its lack of understanding and can therefore be labeled as unattentive.

The attentive public has views on policy issues and will take positions for or against a given policy. There is strong correlation between the level of education and income and the degree of participation within this group. The group can be subdivided further on the basis of its access to technical information and its competence in handling this information. The division is made on the basis of two groups, technical and nontechnical. The technical public can be further subdivided into nuclear specialists composed of the nuclear industry and the general scientific community. Nuclear specialists have been trained in nuclear scịence and ịclude physicists, chemists, and engineers. In general, these people have made deep, personal commitments to nuclear science. The nuclear industry has made large capital investments over the years and is interested in ensuring stability for these investments. The most credible, critics of nuclear energy come from the general scientific community.

The nontechnical attentive population includes organized, articulate special-interest groups such as national environmențal organizations. Their understanding of the complexities surrounding nuclear energy is of ten surprising and appears to be growing. The second nontechnical segment is the local population that may feel threatened by a particular project; its interests are personal, and its arguments are likely to be emotional. and often peripheral to its real concerns. The last group is the remaining general public, which tends to possess generalized nuclear energy perceptions that slowly change as issues emerge and are debated.

It should now be obvious that different means of participation must be effected for each of the major publics listed above. They have differing interests and levels of knowledge and understanding, and they offer different contributions to the planning process. For instance, there is little value in involving the attentive general public directly in the development process; its members have little personal interest, and no special knowledge to contribute. On the other hand, local citizens 
have a great deal at stake and possess a unique understanding of the local situation not available by other means. Each pubiic should therefore be brought into the planing process at the appropriate time and for the type of involvement best suited to its members. The scientific community can offer assistance early in such matters as setting technical criteria and later in judging the technical feasibility of proposed solutions. Environmental groups can be polied for environmental values and later asked to respond to specific plans. Local citizens can actively participate in creating plan's and can react to proposed 'plans.

Much public participation consists 'of a perfunctory dissemination of information, a one-way 'communication from the developer to the pubiic. This is usually done without recognizing that there are many publics, each requiring information tailored to its special needs. For example; an EPA hearing is often packed' with technical jargon'beyond the comprehension of interested locals, while the press releases of utilities are often at such a low level as to frustrate sophisticated special-interest groups. The formal hearing process has evolved to satisfy the need for. public participation, but, because all publics must be served by this single process, it satisfies almost no one. A particular development'. project should therefore plan to integrate an array of public'participation procedures into its project design, which might include such procedures as press releases, private briefings, advisory panels, technical seminars, formal hearings, review procedures, and a set of promising techniques - known as group processing techniques - to be discussed in this report.

The effort to clean up contaminated facilities has relatively limited objectives, and its budget for public participation must be justified against these objectives. For instance, it would be difficult to justify the education of the general public on radioactive waste matters under this effort. Thus, the emphasis on public participation will likely be restricted to informing the management team charged with drawing up specific plans and fulfilling the obligation of these decisions makers to reveal their intentions relevant to those plans. However, for participants not to feel co-opted, they must be made to understand that their informational input is respected and they are capable of 
influencing real decisions. They must be (1) polled before plans are. formulated and (2) allowed to react to preliminary plans or to a set of alternatives once they become available.

It is not possible to involve more than a small part of any public in any given project because of cost and logistic problems in dealing with large numbers of people. As a result, some means of selecting a representative group of each of the various publics must be employed. A. simple technique, ${ }^{13}$. the Power Attribute Method, successfully used for this purpose is based on verbal (often via telephone) polling of each

public. The individuals contacted are asked to nominate opinion leaders among their group. Such leaders do not necessarily hold formal positions of power because it has been hypothesized by the creators of this nomination approach that opinion leaders are'in tune with their.group's positions or leading their groups to new positions even if they are not in formal leadership roles. The nomination approach eventually becomes a process of reducing a list of nominees to a manageable and representative set, using the polled input.

Involving people with conflicting points of view in a complex decision process is a difficult task but is facilitated by a set of procedures, known as group processing techniques, that has come into common use in the last decade. Several applications of these techniques are possible in the cleanup effort, and these are suggested in the design proposed in this report. The next section describes briefly the principles underlying these techniques and discusses several of the techniques available.

\subsection{Group Processing Techniques}

The grovilitg success of ustuy gruup processing techniques to solve a wide range of complex problems is based on an evolving and expanding understanding of how people interact. Whenever two or more people interact, there is a group process at work, and certain recognized principles come into play. By adapting these principles to a particular task through careful planning and implementation, including the use of specific techniques, it is possible to facilitate the work of the group 
charged with the task. The benefits of such facilitation are many; they include (1) support for the group in such matters as establishing goals, identifying problem elements, and evaluating decisions; (2) encouragement of higher-than-normal levels of creativity, and (3) increased motivation and involvement of group membèrs. Thus effective group processing techniques carefully structure group activities in such a way as to increase the group's'sense of involvement while enhancing their effectiveness and creativity. Such techniques impose a higher level of structure than is normally applied to the solution of complex, valueladen problems, but in no way do the techniques require the raw manipulation of group members. Experience has shown that attention to the principles of group processing protects the rights and integrity of individual group members while satisfying their needs for group acceptance and participation. It is generally conceded that manipulative procedures meet resistance and fail.

The success or failure of group processing sessions depends in large measure on how much emphasis is placed on social dynamics. Thus the designer of a group session must consider such things as the need to control dominance; the need for personal gratification on the part of participants; ways to handle conflict, ways to stimulate group creativity, and ways to encourage risk; and many others. This commonly means setting up mechanisms whereby the group can perform these functions itself without the need for external dictate.

Many of the tasks to be accomplished in the cleanup effort would be aided by using facilitated groups. In addition to the demonstrated ability of groups to reach high levels of creativity in producing problem elements such as criteria or management plans, the groups could effectively introduce and represent many of the nontechnical concerns now beginning to play a major role in nuclear waste issues. Thus, they could contribute both broadly based input and a degree of support for the decisions of the team, most of which include nontechnical concerns. Individual group members involved in creating criteria or plans are likely to become advocates of the criteria or plans they help to create, thereby providing support for the management plans ultimately selected. 
For brevity, only two of the many group proccssing techniques are specifically called out in the proposed process. However, there are a number of other places in the general process where either formal techniques or the principles of group processing can be applied. Several of these places are pointed out without suggesting specific procedures.

\subsubsection{The Nomina1 Group Technique}

The Nominal Group Technique (NGT) ${ }^{14}$ is especially noteworthy because it is based on sound psychosocial principles while still maintaining a high degree of structure. It has proved to be an effective and popular tool for problem-element identifying and ranking.

The NGT is essentially a structured group meeting in which a silent, individual activity for generating ideas (nominal activity) precedes an interactive group activity in which the ideas generated are discussed and clarified. It consists of the following sequence of steps:

1. A carefully thought-out question is presented to a group of four to eight participants by a facilitator. A number of groups may run concurrently, though independent of one another, if more than eight participants are involved.

2. Each group member is asked to write silently ideas for a specified period of time.

3. Ideas are collected and listed on a flip chart in a round-robin fashion, with each participant offering an idea in turn until all ideas are exhausted. If anonymity is desired, an independent "facilitator" team can take the suggested ideas, list them at random on the flip chart, and present the results to the group.

4. Listed ideas are clarified by the group.

5. Each person ranks the modified list of ideas; votes are collected and the results posted. 
6. Rankings are discussed and ideas again modified; limited debate $i_{\text {i }}$ permitted.

7. A second vote is taken.

The steps listed above may take one-half to several days, depending on the complexity of the problem and the amount of agreement present.

\subsubsection{The Take-Part Process}

The Take-Part Process is a group problem-solving technique that has evolved in recent years under the leadersh1p of Lawrence Halprin. ${ }^{5}$ The technique is based on the premise that all people have creative potential and that, when they interact in groups, this creativity can be unleashed and enhanced. The process design has elements borrowed from a number of fields and consists of a cycle made up of four steps, the RSVP (resources, scores, valuation, and performance). The RSVP is both a framework for the process and a guide for group members. Because it is cyclical, it can accept input and change as well as shift objectives to adjust to new ideas created during the process.

Resources are both the data used as group input and the objectives related to the problem at hand, which help to guide the overall process. Data consists of information gathered for the workshop by its planners and the information, values, and experience brought to the workshop by its participants. Scores are group tasks designed by the planners and assigned to the participants in the course of the workshop; they serve many purposes. For instance, scores can (1) introduce the group to what is expected of them during the workshop, (2) free participants to perceive their environment in new and stimulating ways, (3) be introduced if conflict or resistance becomes visible and be used to defuse the conflict, and (4) celebrate completion of the process.

Performance is the activity of the group in carrying out an assigned score. An example is the way in which a group complies with the score to create a plan to remove neighborhood blight. Performance is usually left to the group, with the workshop leaders remaining vigilant to conflicts and blocks in the creative process. 
No comments or critiques are encouraged during performance of scores because this would limit the creative exploration of ideas and aiternatives. Upon completion of major scores, critiques or valuation sessions are held to generate feedback to workshop leaders, analyze performance, and give the participants a feeling of accomplishment. Workshop leaders modify subsequent scores as appropriate from the feedback gathered in the valuation sessions.

When well designed and implemented, the Take-Part Process has produced creative solutions and a high level of satisfaction in those participating. The process offers the site-management team a means of involving people with unique local understanding or with special interests in creating site-management plans, and it deserves further. consideration.

The next section focuses the previous discussion on a process design that offers DOE and NRC flexibility, broad participation, and a systematic method for executing their responsibilities in the cleanup effort.

\subsection{The Management Plan Development Process}

Continuity of responsibility and authority is essential to a successful cleanup effort. This can be effected best by a small management team of four to five members that follows a group of sites from initial information gathering through final plan implementation. At least one member of the team, preferably the leader, should be a DOE or an NRC representative. Such direct DOE or NRC involvement would (1) link agency responsibility more directly to actual site decisions, (2) allow the agency to be more sensitive to local and state concerns, and (3) allow the agency to defend and represent management plans more successfully during both the review phase and the appropriation arguments in Congress. Other team members should represent diverse interests such as the EPA, the state, and perhaps the land-management professions such as landscape architecture.

The use of a tightly organized, interacting management team whose members possess diverse experience and disciplinary training gives the 
team greater authority to handle complex problems. Each member has underdeveloped abilities in initiative, originality, and leadership, which are challenged and nutured by other group members. By being united in the actions of a small group, these abilities tend to emerge and grow stronger. In addition, because the team is confronted with competing value systems and the need to achieve an equitable solution, it will develop an improved concept of the common good.

The total. immersion in the problem demanded by the proposed planning process together with a commitment to seeing the problem through to the end requires full-time involvement of team members. During the process they are expected to perform as decision makers, planners, process experts, process managers, educators, discussion participants, negotiators, and sensitive listeners.

The team can never maintain absolute control of the decision process or its associated schedule. There will be unanticipated events and reactions, delays and irregular rates of progress, periods of enthusiasm and discouragement, and periods of activity and apathy. However, the psychology and publicly announced commitment of the team act as stabilizing influences, carry the process through periods of reversal, and keep it from drifting into wasteful sidetracks.

Before it can begin to consider a group of sites, the management team requires a great deal of site-specific data and a set of criteria with which to guide its actions. The criteria should be general, be much like a set of objectives, and be applicable to all sites within a major group such as the formerly used MED/AEC or mill-tailings sites. They should contain technical (e.g., permissible radiation-exposure levels), environmental, institutional, and social components. However, the criteria should not be so specific as to limit the flexibility of the management team in creating solutions to the unique problems posed by each site. Because the development of criteria must precede the collection of data by the site-management teams, criteria development should be accomplished as quickly as possible.

Criteria identification is an ideal application for group processlng, particularly the Nominal Group Technique. To this end, eight individuals especially knowledgeable about contamination problems to be 
addressed could be invited to participate in a 3-day nominal group session led by a trained facilitator for the purpose of identifying criteria. All group members should possess a thorough understanding of the technical issues likely to evolve into criteria. At the same time, some group members should have personal experience with contamination problems and should be able to represent such areas as land-use conflict, institutional difficulties in regulation and management, public attitude, and environmental impact. As a minimum, one representative each from the primary agency, DOE or NRC, and from EPA should participate. These carefully selected experts should be charged with the.important task of focusing and organizing the work done to date on technical criceria while adding their own unique insights. Additionally, they should create a supplementary set of criteria covering social, institutional, and environmental concerns. They, should be made to, understand that the criteria they specify will carry the endorsement of DOE or of. NRC and will represent the initial input for a review process from which criteria will be created for use in actual site-plan development.

The morning of the first day, is devoted to listing a small number.. of possible technical criteria. Most of this time is spent in discussing the criteria listed, which is essential because of the complexity of the technical issues involved. By the end of the first morning, steps A through $E$ of the Nominal Group Technique described in Sect. 3.3.1 will be completed for a limited set of criteria.

In the afternoon, the process is repeated, starting anew at step $A$ and going through to completion. In this second run, a more detailed. and comprehensive list of technical criteria is created.

The second day uses the Nominal Group Technique and the same general criteria to create a set of nontechnical criteria.

The third day is devoted to polishing and refining the criteria created. Attention is given to such things as creating one integrated list from the technical and nontechnical lists, combining and eliminating criteria where possible, and improving the wording of individual criteria. 
The output of the 3-day session is documented and submitted to informal review before the criteria are placed in the Federal Register for general public review.

The forms of communication adopted for this review step are controlled by the considerations discussed under Public Participation, Subsect. 3.2. The publics to be involved can be identified by means of the hierarchy suggested in Subsect. 3.2, and representatives of each of these publics in turn can be determined by the Power-Attribution Method. In this method, a small nucleus of well-known individuals in each group identified are asked to nominate other influential members of their group. These individuals, in turn, nominate more members, and the process continues until a subset of duplicated nominees emierges. The subset then becomes the pool of interest-group representatives used in the various public participation efforts of the cleanup activity. With this step accomplished, the management team can notify the various groups of its intention to create management plans and thereby reduce some of the surprise opposition that so of ten emerges late in the decision process.

Criteria review is a logical first step in opening a dialog with the various publics. Communication devices employed in the review and notification step range from simple news releases to small, highly interactive group sessions with technical experts. The channels of communication established at this step in the process are maintained through subsequent process steps, both for the sake of continuity and to build a constituency favorable to the ultimate solution to be proposed.

The steps described above for identifying and refining criteria are portrayed graphically in steps 1 and 2 of Fig. 1. The criteria form only one of three data sources used by the site-management team. Step 3 represents the gathering of technical and cost data for each site, which is needed to create viable site alternatives. A large amount of this data is available from recent surveys, but the management team should retain the option of commissioning additional data as needed.

Step 4 departs from the traditional engineering approach used. in past decontamination and decommissioning efforts in that it makes available to the management team the results of an independent analysis. of 


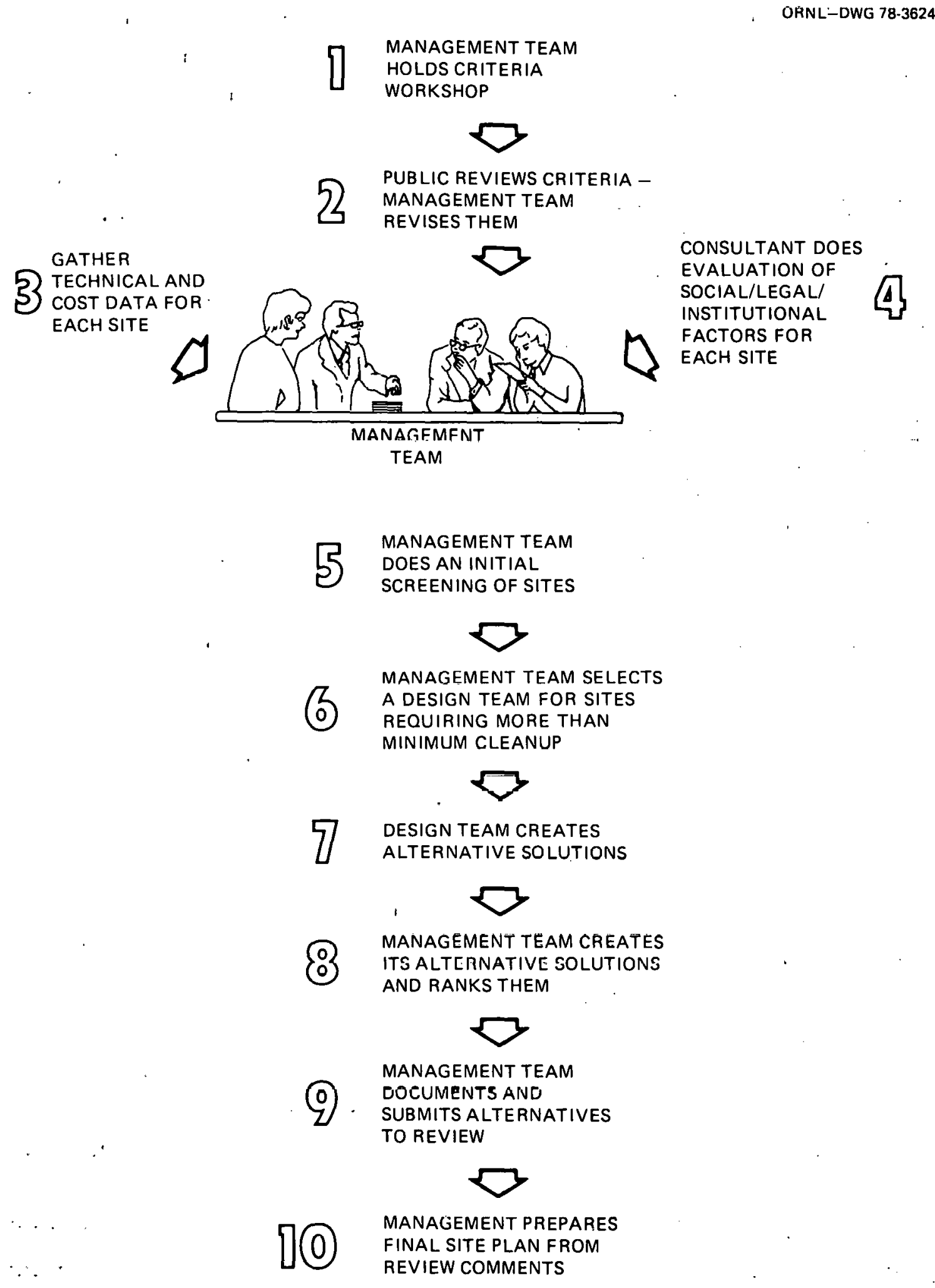

Fig. 1. Process for developing site-management plans. 
social, legal, and institutional factors that affect a particular site. This in effect recognizes such factors as being equal in importance to the technical and cost factors that are more likely to be considered exclusively in a traditional approach. It is suggested that the evaluation of social factors be the work of an independent consultant, perhaps a sociologist or political scientist from a nearby university, who is familiar with the local situation at each site.

The analysis proposed for the consultant falls short of the longterm, objective study preferred by social scientists; it is, rather, a short-term (2 months) identification of pertinent data and issues. It is much more related to the work of a thorough investigative reporter than to that of a social scientist doing independent research.

With the necessary information in hand, the site-management team can begin to develop a set of alternatives for each site. In step 5 the team screens all sites for which they have responsibility against the cleanup criteria to determine those sites requiring only minimum cleanup. Plans are drawn up directly for this subset without generating alternatives by means of steps 6,7 , and 8 . The experience and confidence gained by planning for this subset of sites requiring minimum cleanup will prepare the team for more complex decisions and management plans. The remaining sites, expected to be few in number, require more attention because of their potential. for extremely high costs and difficult technical or institutional problems. The most efficient and equitable way to deal with these sites is to develop alternative site-management plans (most likely differentiated on levels of cost) that are subjected to public debate before a final single recommendation is made. Although the development of the final recommendation is the responsibility of the management team, creative alternatives can come most effectively from special design teams working in the framework of the Take-Part Process. Two design teams consisting of four or five persons with knowledge of the site and an understanding of the contamination problem are selected (step 6). Ideally, the team includes at least one local citizen and one person trained in land-management skills. The teams are assigned the task of designing the cleanup of a given site, using the general criteria - one team to use an unrestricted budget and the other team to 
use a restricted budget (step 7). The design task is accomplished in an intensive 3-day workshop under the leadership of individuals trained in the Take-Part Process. Technical and social data are made available to the design teams, and resource people in these areas (such as the consultant who created the social data relative to the site) will stand by during the workshop to assist further. The teams are encouraged to create and explore solutions likely to have high levels of acceptability in the eventual review process. The plans developed are carefully documented and supplied to the management team following the workshop. In step 8 , the management team creates a range of practical alternatives from the design-team input and from their own understanding of the greater decontamination and decommissioning problem. Successive. modifications make it possible to bring proposed alternatives more in line with the realities of the real world. Thus, the design team recommendations are strengthened through the broader understanding of the management team, and the management team recommendations are modified in turn by the public review process. This procedure recognizes that the decision on a contaminated site is political as well as intellectual and that the final solution can be improved through successive iterations. The alternatives generated by the management are ranked in step 8 . A number of formalized techniques ${ }^{10}$ are available to the management team in considering trade-offs and performing the ranking function. Inasmuch as such techniques can lend a great deal of objectivity to the ranking process, they should be employed if possible. One technique, Bishop's Factor Profile, 17 is of particular interest because of its simplicity and ease of use. In this method, alternatives are first profiled relative to important factors; that is, the original criteria created in step 1 such as total cost, level of monitoring, degree of local disruption, etc., are measured for each alternative and then grouped and displayed by three major areas - environmental, economic, and social. The management team then makes judgemental pair-wise comparisons of alternatives by the major groupings and ranks the alternatives as to their desirability. In particular, the team would first compare the various alternatives on the environmental and social factor trade-offs and rank order them on this basis. It then would compare this ranking 
to a cost ranking and evaluate the trade-offs in terms of their cost. A final ranking of alternatives is created by this process. The uncertainties associated with each measure are considered as trade-off decisions are made. Finally, the rationale and the factual basis for each alternative is documented and the total package ( $\mathrm{plan}$ and supporting material) submitted to the review process (step 9).

In soliciting responses during the review process, the management team should use the various publics involved in step 3 . Communication with these publics would again be designed to fit each public. For instance, interaction with the scientific community has a different emphasis and level of detail than interactions with local citizen groups. It is especially important to create different materials for presentation to these various groups. Group processing techniques can facilitate at least some of the communication that occurs during this phase. Formal hearings may or may not be a part of the review process. The various responses from the review process are used to modify alternatives. One plan is selected (step 10), and the basis for the selection is carefully documented for the eventual appropriation submission. The function of the management team then changes to one of defending and explaining its recommendations. Further modifications may be required during the funding process, but the essential planning tasks of the management team are completed with step 10 . However, the continuity of the management team should be maintained into the implementation phase if at all possible. This may be possible by carrying at least one team member into the implementation phaoc. 


\section{THIS PAGE}

\section{WAS INTENTIONALLY LEFT BLANK}




\section{CONCLUSION}

Societal problems are becoming increasingly complex because evolving technology has intertwined the various segments of society with each other and with the natural environment in patterns of mutual dependency and impact. This is clearly the case with the cleanup of contaminated propertles. Increased public concern, changing environmental values, new ethical questions, and tighter standards hamper solutions to decontamination and decommissioning. A systematic planning process that incorporates recent advances in such areas as policy analysis, systems analysis, and the social sciences can greatly facilitate the creation of a viable solution to the cleanup effort. To be effective, such a process must possess the attributes of continuity of responsibility, centralized authority, flexibility, consensus seeking, alternative plan generation, objectivity, and sensitivity to various interests and the institutional setting.

A tentative design for such a process is suggested in Sect. 3 of this report. It has the attributes described and uses at least two proved group processing techniques to deal with the multidimensional, multigroup nature of the cleanup problem. A number of benefits are obtained through the explicit consideration (by means of public participation) of a broad range of concerns and by incorporating these concerns into alternative solutions:

1. A more creative set of alternatives is probably generated than in a closed-decision process. It is likely that at least one of these solutions will result in a "permanent" solution for a majority of the interested groups.

2. The DOE or NRC will be forced to consider in depth alternatives that they would normally dismiss early in the process or that might never occur to them. While this will undoubtedly seem like an imposition to overworked DOE or NRC staff members, it will give them the information needed to meet directly the ultimate challenge of the advocates of undesirable alternatives, and it should allow them to plece together 
various alternatives for creating a final set of alternatives more acceptable to those with the power to obstruct or cancel agency plans.

3. By requiring clear statements of criteria and alternatives, it is possible to specify data needs more clearly. The cost of data gathering should therefore be reduced, and the actual data gathered should be more accurate and appropriate to the decision.

4. Trade-offs are handled in a systematic, open procedure, which should eliminate the mystery and suspicion normally surrounding this step.

5. The final decision can be traced by means of documentation through the process, making it defendable.

In terms of the total cost of the cleanup effort and the inefficiency of. traditional planning approaches, the proposed process has many advantages and is competitive. Even more important, it has a higher probability of delivering an acceptable management plan than do traditional engineering-based approaches.

What has been proposed is only a sketch of a total planning process; if the concepts outlined seem sound, DOE and NRC should take the next step and initiate plans for completing the design detalls to cover the cleanup of contaminated nuclear facilities that are no longer in use. 


\section{REFERENCES}

1. E. S. Quade, Analysis for Public Decisions, American Elsevier, New York, 1975.

2. W. H. Jordan, quoted in "Jordan Disputes NRC on Radon Emission Levels," The Oak Ridger, Oak Ridge, Tenn., Nov. 29, 1977, p. 1.

3. M. B. Biles and R. H. Kennedy, "Land Use Problems of Uranium Mill Tailings," presented at Atomic Industrial Forum Conference on Land Use and Nuclear Facility Siting, Denver, Colo., July 18-21, 1976.

4. Comptroller General, Cleaning Up the Remains of Nuclear Facilities A Multibizzion Dolzar Program, FMD-77-46, Report to the Congress,... General Accounting Office, Washington, D.C. (June 1977).

5. Environmental Protection Agency, Office of Radiation Programs, Environmental Analysis Division, Environmental Analysis of the Uranium Fuel Cycle. Part 1. Fuel Supply, EPA-520/9-73-0003-B, U.S. Government Printing Office, Washington, D.C. (November 1973), pp. $72-74$.

6. J. J. Swift, J. M. Hardin, and H. W. Calley (Environmental Protection Agency, Office of Radiation Programs, Environmental Analysis Division), Potential Radiological Impact of Airborme Releases and Direct Radiation to Individuals Living Near Inactive Uranium Mill Taizings Piles, EPA-520/1-76-001, U.S. Government Printing Office, Washington, D.C. (January 1976).

7. U.S. Department of the Interior, Bureau of Mines, Report on Investigation No. 8009, Pittsburgh, Pa.

8. D: D. Comey, "The Legacy of Uranium Tailings," BulZ. At. Sci., 31: 43 (1975).

9. L. M. Bronfman, Public Debate of Radioactive Waste Management: Its Implications for Publio Acceptance, to be published as an ORNL report. 
10. F. F. Haywood et al., Assessment of Radiological Impact of the Inactive Uranium-Mill Tailings Pile at Salt Lake City, Utah, ORNL/TM-5251 (November 1977).

11. R. W. Leggett et a1., Interim Report-Radiological Survey of the Property at 9200 Latty Avenue, Hazelwood, Missouri, to be published as an ORNL report.

12. B. Greer-Wootten and L. Mitson, Nuclear Power and the Canadian Public, Institute for Behavioural Research, York University, Toronto, Canada, 1976, p. 69.

13. M. Burgess, Negro Leadership in a Southerm City, University of North Carolịna Press, Chapel Hill, 1962.

14. A. L. Delbecq it al., Group Techniques for Program Planning: A Guide to Nominal Group and Delphi Processes, Scott Foresman and Co., Glenview, I11., 1975.

15. L. Halprin and J. Burns, Taking Part: A Workshop Approach to Collective Creativity, MIT Press, Cambridge, Mass., 1974.

16. B. F. Hobhs and A. H. Voelker, Analytical Multiobjective DecisionMukirly Tecirriques and power plant Siting: A Survey and Critique, ORNL-5288 (February 1978).

17. A. B. B1shop, "An Approach to Evaluating Environmental, Social, and Economic Factors in Water Resources," Water Resour. BulZ. 8(4): 724 (1972). 
ORNL/TM-6298

Distribution Category UC-70

\section{INTERNAL DISTRIBUTION}

$\begin{aligned} \text { 1. } & \text { S. E. Beall } \\ 2 . & \text { D. J. Bjornstad } \\ 3 . & \text { J. T. Blackmon, Jr. } \\ \text { 4. } & \text { B. H. Bronfman } \\ \text { 5. } & \text { R. S. Carlsmith } \\ 6 . & \text { R. M. Davis } \\ \text { 7-11. } & \text { H. W. Dickson } \\ \text { 12. } & \text { J. E. Dobson } \\ \text { 13. } & \text { R. C. Durfee } \\ \text { 14. } & \text { W. Fulkerson } \\ \text { 15. } & \text { F. F. Haywood } \\ \text { 16. } & \text { R. B. Honea } \\ \text { 17-66. } & \text { D. G. Jacobs } \\ 67 . & \text { S. V. Kaye } \\ 68 . & \text { A. S. Loeb1 } \\ 69 . & \text { J. W. Miche1 } \\ 70 . & \text { D. C. Parzyck }\end{aligned}$

71. E. Peelle

72. C. H. Petrich

73. H. Postma

74. C. R. Richmond

75. P. S. Rohwer

76. M. W. Rosenthal

77. T. H. Row

78. R. L. Spore

79. C. C. Travis

80-193. A. H. Voelker

194. D. P. Vogt

195. T. J. Wilbanks

196-197. Central Research Library

Documenl Reference Section

198-199. Laboratory Records

200. Laboratory Records (RC)

201. ORNL Patent Office

202-204. Technical Publications Department

\section{EXTERNAL DISTRIBUTION}

205. K. R. Baker, Division of Operational and Environmental Safety, Department of Energy, Washington, DC 20545

206. Nat Barr, Division of Technology Overview, Department of Energy, Washington, DC 20545

207. Paul Baxter, Forestry, Fisheries, and Wildlife Division, Tennessee Valley Authority, Norris, TN 37828

208. M. T. Beatty, Natural and Environmental Resources, University of Wisconsin-Extension, 501 Extension Building, 432 North Lake Street, Madison, WI. 53706

209. Walter Belter, Division of Biomedicine and Environmental Research, Department of Energy, Washington, DC 20545

210. Samuel Berman, Lawrence Berkeley Laboratory, Office of Environmental Policy Analysis, Berkeley, CA 94720

211. Robert Bernerd, Office of Standards Development, U.S. Nuclear Regulatory Commission, 5650 Nicholson Lane, Rockville, MD 20555

212. William R. Bibb, Oak Ridge Operations, Federal Office Building, Room 2047, Oak Ridge, TN 37830

213. Wallace Bowman, Congressional Research Service, Library of Congress, Washington, DC 20540

214. Harvey Brooks, Dean of Engineering and Applied Science, Harvard University, Cambridge, MA 021.38

215. John Burnham, Battelle/Pacific Northwest Laboratory, P.0. Box 999, Richland, WA 99352 
216. Eljison Burton, Assistant Director for Environmental Analysis, Planning, Analysis, and Evaluation, Department of Energy, Washington, DC 20545

217. Jack Campbe11, Division of Research, Appalachian Regional Commission, Washington, DC 20235

218. Paul Cho, Division of Technology Overview, Department of Energy, Washington, DC 20545

219. Donald P. Cleary, Cost Benefit Branch, U.S. Nuclear Regulatory Commission, Washington, DC 20555

220. George A. Cochran, State Fuel Coordinator, 1307 Woolfolk State office Building, Jackson, MS 39205

221. J. A. Coleman, Deputy Director, Office of Technology Impacts, Department of Energy, Washington, DC 20545

222. Enrico F. Conti, Office of Standards Development, U.S. Nuclear Begillatory Commission, Wash1ngtun, DC 20555

223. Raymond D. Cooper, Assistant Director for Integrated Assessment, Department of Energy, Washington, DC 20545

224. Frnest Coriz, Energy Resources Buard, Box 2770, Santa Fe, NM 87501.

225. Paul Craig, Lawrence Livermore Laboratory, Office of Environmental Policy Analysis, P.O. Box 808, Livermore, CA 94550

226. William T. Crow, Office of Nuclear Material Safety and Safeguards, U.S. Nuclear Regulatory Commission, 191 b Éastèrn Avenue, Sllvel Springs, MD 20555

227. Jerry Davis, Nuclear Regulatory Research, U.S. Nuclear Regulatory Commission, Washington, DC 20555

228. L. J. Deal, Assistant Director, Division of Operational and Environmental Safety, Department of Energy, Washington, DC 20545

229. Frank J. Doyle, Bureau of Mines, U.S. Department of the Inter1or, Pittsburgh, PA 15213

230. David Drake, Administrator, Kentucky Center for Energy Research, Ir UII Wulks Pike, Lexington, KY 40505

231. Kell Duekèr, Department of Geography, University of Iowa, Iowa City, IA 52240

232. John Fox, Battelle-Pacific Northwest Laboratory, P.0. Box 999, Richland, WA 99352

233. S. David Freeman, Tennessee Valley Authority, 400 Commerce Avenue, Knoxville, TN 37902

234. Joseph Gabbard, Ozark Regional Committce, Comittee Staff off,1,e, Suite 109, Evergreen Place, 1100 North University Avenue, Little Rock, AR 72207

235. Paul Gerhardt, Division of Technology Overview, Department of Energy, Washington, DC 20545

236. J. H. Gibbons, Environment Center, University of Tennessee, Knoxville, TN 37920

237. M. A. Goldberg, Faculty of Commerce, Univers1ty of British Columbia, Vancouver 8, British Columbia, Canada

238. Charles Gottschalk, Institutional Relations, Department of Energy, Washington, DC 20545

239. Leonard D. Hamilton, Brookhaven National Laboratory, Office of Environmental Policy Analysis, Upton, NY 11973 
240. E. J. Hanrahan, Office of Policy Analysis, Department of Energy, Washington, DC 20545

241. Don. F. Harmon, Office of Standards Development, U.S. Nuclear Regulatory Commission, 5650 Nicholson Lane, Rockville, MD 20555

242. Ted Heintz, Office of Policy Analysis, U.S. Department of the Interior, Washington, DC 20545

243. Ed Helminiski, National Governor's Conference, Hall of the States, 444 North Capitol Street, NW, Washington, DC 20001

244. Darry1.L. Hesse1, Pacific Northwest Laboratories, Office of Environmental Policy Analysis, Battelle Boulevard, P.0. Box 999, Richland, WA 99352

245. Jerry Hinkle, Division of Technology Overview, Department of Energy, Washington, DC 20545

246. Richard Hold, Policy Analysis, Department of Energy, Washington, DC 20545

2.47. H. Hollister, Director, Divisiun of Operational and Environmental Safety, Department of Energy, Washington, DC 20545

248. L. John Hoover, Argonne National Laboratory, 9700 South Cass Avenue, Argonne, IL 60439

249. P. W. House, Director, Office of Technology Impacts, Department of Energy, Washington, DC 20545

250. Thomas Hughes, Institutional Relations, Department of Energy, Washington, DC 20545

251. Gordon Jacobs, Program Manager, Environmental Systems and Resources, National Science Foundation, 1800 G Street, NW, Room 415, Washington, DC 20550

252. Jacob Kastner, Office of Standards Development, U.S. Nuclear Regulatory Commission, 5650 Nicholson Lane, Rockville, MD 20555

253. R. H. Kennedy, Divieion of Enviromental Control Technology, Department of Energy, Washington, DC 20545

254. Charles Killpack, Research Associate, The Holcomb Research Institute, Butler University, Indianapolis, IN 46208

255. Fritz R. Krause - 5443, Sandia Laboratories, Office of Environmental Policy Analysis, P.O. Box 5800, Albuquerque, NM 87115

256. Harry H. Landon, Office of Nuclear Regulatory Research, U.S. Nuclear Regulatory Commission, Washington, DC 20555

257. George Leppert, Argonne National Laboratory, Office of Environmental Policy Analysis, 9700 South Cass Avenue, Argonne, IL 60439

258. James L. Liverman, Assistant Administrator for Environment and Safety, Department of Energy, Washington, DC 20545

259. Ronald K. Lohrding, Los Alamos Scientific Laboratory, Office of Environmental Policy Analysis, Los Alamos, NM 87545

260. James Lutz, Department of Political Science, West Virgina University, Morgantown, WV 26506

261. P. R. Magno, U.S. Nuclear Regulatory Commission, Mail Code 396-SS, Washington, DC 20555

. 262. J. R. Maher, Division of Technology Overview, Department of Energy, Washington, DC 20545

263. Roger Mattson, Office of Standards Development, U.S. Nuclear Regulatory Commission, Washington, DC 20555 
264. C. R. Meyers, Water Resource Cuuncil, 2120 L Street, NW, Washington, DC 20037

265. W. A. Mills, Environmental Protection Agency, Room 635 Waterside Ma11 Eást, $401 \mathrm{M}$ Street, SW, Washington, DC 20460

266. W. E. Mott, Director, Division of Environmental Control Technology, Department of Energy, Washington, DC 20545

267. C. W. Myers, Planning and Analysis, Department of Energy, 20 Massachusetts Avenue, Washington, DC 20545

268. Joe Nash, Office of Environmental Policy Analysis, Department of Energy, Washington, DC 20545

269. Emil L. Nelson, Planning and Analysis, Department of Energy, Washington, DC 20545

270. Ken Nemeth, Southern Interstate Nuclear Board, One Exchange Place, Suite 1.230, At.lanta, GA 30341

271. Randolph Newton, Division of Technology Overview, Department of Energy, Washington, DC 20545

272. Bernard J. Niemann, Jr., Landscape Architecture, University of Wisconsin, Madison, 25 Agriculture Ha11, Mádisoñ, WI 33906

273. C. T. N. Paludan, Chief, EF-02, Farth Resources Office, Marshal1 Space'Flight Center, Huntsville, AL 35812

274. R. Ramsey, Division of Environmental Control Technology, Department of Energy, Washington, DC 20545

275. : David J. Rose, Department of Nuclear Engineering, Room 24-210, Massachusetts Institute of Technology, Cambridge, MA 02139

276. D. M. Ross, Division of Operational and Environmental Safety, Department of Energy, Washington, DC 20545

277. Leland C. Rouse, Office of Nuclear Material Safety and Safeguards, U.S. Nuclear Regulatory Commission, 7915 Eastern Avenue, Silver Springs, MD 20555

278. C. R. Schuller, Human Affairs Research Center, Battelle-Seattle, $4000 \mathrm{NE}$ 41st Street, Seattle, WA 98105

279. K. L. Shelton, Department of Research Development, Michigan State University, East Lansing, MI 48823

280. Joe Sherman, Division Director, Policy Research and Development, U.S. Department of Housing and Urban Development, 4517 th Street, SW, Room 8158, Washington, DC 20410

281. Clifford V. Smith, OFfice of Nuclear Material Safety and Safeguards, U.S. Nuclear Regulatory Commission, 7915 Eastern Avenue, Silver Springs, MD 2.0555

282. V. Kerry Smith, Resources for the Future, 1755 Massachusetts Avenue, NW, Washington, DC 20036

283. M. R. Spangler, Cost-Benefit Analysis Branch, Directorate of Licensing, Department of Energy, Bethesda, MD 20014

284. Carl Steinetz, Department of Landscape Architecture, Gund Hall, Harvard University, Cambridge, MA 02138

285. Keith G. Steyer, Office of Standards Development, U.S. Nuclear Regulatory Commission, 5650 Nicholson Lane, Rockville, MD 20555

286. Lawrence Susskind, Associate Professor of Urban Studies and Planning, Massachusetts Institute of Technology, Cambridge, MA 02139

287. W. N. Thomasson, Division of Technology Overview, Department of Energy, Washington, DC 20545 
288. L. M. Tombaugh, Director, Division of Advanced Environmental Research and Technology, National Science Foundation, 1800 G Street, NW, Room 415, Washington, DC 20550

289. George Thessel, Office of Public Understanding, National Science Foundation, $1800 \mathrm{G}$ Street, SW, Washington, DC 20555

290. Albert C. Tsao, Administrator, Energy Planning Division, Montana State Department of Natural Resources, 32 S. Ewing Street, Helena, MT 59601

291. Jane Upchurch, EPA-IERL, Mail Stop 63, Research Triangle Park, NC 27711

292. Richard Vannoy, Conservation and Environment, Federal Energy Agency, 12th and Pennsylvania, Washington, DC 20467

293. Bruce W. Wachho1z, Division of Technology Overview, Department of Energy, Washington, DC 20545

294. Roscoe Ward, Institutional Relations, Department of Energy, Washington, DC 20545

295. A1 Wehe, Energy Strategies Branch, Environmental Protection Agency, Research Triangle Park, NC 27709

296. E. R. (Ted) Williams, Director, Division of Policy Analysis, Office of Technology Impacts, Department of Energy, Washington, DC 20545

297. Eric Willis, Institutional Relations, Department of Energy, Washington, DC 20545

298. H. Brown Wright, Division of Navigation, Development, and Regional Studies, Tennessee Valley Authority, Knoxville, TN 37902

299. Frank W. Young, Senior Coordinator for State Agencies, Mail Stop 11700, U.S. Nuclear Regulatory Commission, Washington, DC 20555

300. Research and Technical Support Division, Oak Ridge Operations, Department of Energy, Oak Ridge, TN 37830

301-567. Distribution as shown in TID-4500 under Nuclear Waste Management category ( 25 copies - NTIS) 